\title{
Potential sources of carcinogenic heterocyclic amines in Chinese mutton shashlik
}

\author{
Li Sun $^{\mathrm{a}, \mathrm{b}}$, Feng Zhang ${ }^{\mathrm{a}}$, Wei Yong ${ }^{\mathrm{a}}$, Si Chen ${ }^{\mathrm{a}}$, Min-Li Yang ${ }^{\mathrm{a}}$, Yun Ling ${ }^{\mathrm{a}}$, Xiaogan Chu ${ }^{\mathrm{a}, *}$, Jin-Ming Lin ${ }^{\mathrm{b}, \mathrm{c}}$ \\ anstitute of Food Safety, Chinese Academy of Inspection and Quarantine, Beijing 100123, China \\ ${ }^{\mathrm{b}}$ State Key Laboratory of Environmental Chemistry and Ecotoxicology, Research Center for Eco-Environmental Sciences, Chinese Academy of Sciences, \\ P.O. Box 2871, Beijing 100085, China \\ ${ }^{\mathrm{c}}$ The Key Laboratory of Bioorganic Phosphorus Chemistry and Chemical Biology, Department of Chemistry, Tsinghua University, Beijing 100084, China
}

\section{A R T I C L E I N F O}

\section{Article history:}

Received 7 July 2009

Received in revised form 3 November 2009 Accepted 1 May 2010

\section{Keywords:}

Heterocyclic aromatic amine

Mutton shashlik

\begin{abstract}
A B S T R A C T
Heterocyclic amines (HAs) are formed in muscle meat during its cooking under ordinary conditions. In this work, we measured the concentration of 15 kinds of heterocyclic aromatic amines (HAAs) in mutton shashlik which is one of the most popular dishes in China and provided the basis for efforts to quantify dietary exposure to these compounds. Five mutton shashliks bought in market were determined and the concentrations of Harman, Norharman, DMIP, PhIP and A $\alpha$ C were 0.40-1.36, 0.07-0.50, 0.73-65.07, 0.9025.62 , and $0.39-2.13 \mathrm{ng} / \mathrm{g}$, respectively. The mimic experiments have been carried out in an oven to investigate the influence of time, temperature, flavours, and area of heating surface on the formation of HAAs in ground mutton roasted. The levels of HAAs in cooked meat are highly dependent on the cooking time and temperature and increased with the area of heating surface. Meanwhile, flavours have a different impact because of their various characters.
\end{abstract}

(c) 2010 Elsevier Ltd. All rights reserved.

\section{Introduction}

Mutton, which has rich nutrition and special flavour, is a type of flavoured food in China. Mutton provides high levels of zinc and iron. Also it is a great source of high quality protein, unsaturated fat, trace elements and B Vitamins which are essential for metabolic reactions in the body. Now there is a popular cookery of mutton in China that we call the food mutton shashlik which can be ordered in most restaurants. High temperature, the essential condition of this cookery, can lead to the formation of heterocyclic amines (HAs), especially heterocyclic aromatic amines (HAAs), in heated meat (Bermudo, Ruiz-Calero, Puignou, \& Galceran, 2005; Borgen \& Skog, 2004; Busquets, Bordas, Toribio, Puignou, \& Galceran, 2004; Martín-Calero, Ayala, González, \& Afonso, 2007). Although only trace amounts (ng/g) of these compounds are formed, they are still considered a risk factor for human cancer due to their frequent intake.

HAAs were first isolated from charred meat and fish (Nagao, Honda, Seino, Yahagi, \& Sugimura, 1977). Since 1977, more than 20 HAAs have been isolated and identified from cooked muscle foods (Ohgaki et al., 1984; Övervik, Kleman, Berg, \& Gustafsson, 1989; Wakabayashi, Nagao, Esumi, \& Sugimura, 1992; Wakabayashi \& Sugimura, 1998). Over the years, many researchers have suggested that the formation of HAAs is a result of the condensation of free amino acids, creatine, creatinine, monosaccharides, disaccharides, or dipeptides, which all may act as precursors of

\footnotetext{
* Corresponding author. Tel.: +86 10 85778904; fax: +86 1085791012 .

E-mail address: xgchu@vip.sina.com (X. Chu).
}

HAAs during cooking at high temperature (Jägerstad, Grivas, Olsson, \& Negishi, 1984; Pais, Salmon, Knize, \& Felton, 1999; Skog \& Jägerstad, 1990; Solyakov, Skog, \& Jägerstad, 1999). The International Agency for Research on Cancer (IARC, 1993) has recorded some of these HAAs in monographs. 2-Amino-3-methylimidazo[4,5-f]quinoline (IQ) is classified as a probable human carcinogen (class 2A) and 2-amino-3,4-dimethylimidazo[4,5-f] quinoline (MeIQ), 2-amino-3,4-dimethylimidazo[4,5-f]quinoxaline (MeIQx), 2-amino-1-methyl-6-phenylimidazo[4,5-b]pyridine (PhIP), 2-amino-9H-pyrido[2,3-b]indole (A $\alpha \mathrm{C}), 2$-amino-3-methyl-9H-pyrido [2,3-b]indole (MeAaC), 3-amino-1,4-dimethyl-5H-pyrido[4,3-b]indole (Trp-P-1), 3-amino-1-methyl-5H-pyrido[4,3-b]indole (Trp-P2), 2-amino-6-methyldipyrido[1,2-a:3', $2^{\prime}$-d]imidazole (Glu-P-1), and 2-aminodipyrido[1,2-a:3', $2^{\prime}$-d]imidazole (Glu-P-2) are classified as possible carcinogens (class 2B).

Many purification techniques have been described (Toribio, Busquets, Puignou, \& Galceran, 2007; Toribio, Puignou, \& Galceran, 2000; Vollenbröker \& Eichner, 2000), mainly followed by chromatographic methods including liquid chromatography with ultraviolet (LC/UV) (Vollenbröker \& Eichner, 2000), electrochemical (LC/ ECD) (Bermudo et al., 2005; Martìn-Calero, Pino, Ayala, González, \& Afonso, 2007) or fluorescence detection (Martín-Calero et al., 2007), or gas chromatography with nitrogen-phosphorus selective detection (GC/NPD) (Kataoka \& Kijima, 1997). However, in recent years a large number of works based on the use of either liquid chromatography or gas chromatography in combination with mass spectrometry (MS) have been published (Barceló-Barrachina, Moyano, \& Galceran, 2004; Barceló-Barrachina, Santos, Puignou, \& Galceran, 2005; Barceló-Barrachina et al., 2006; Casal, Mendes, 
Fernandes, Oliveira, \& Ferreira, 2004; Toribio, Moyano, Puignou, \& Galceran, 2002; Turesky, Taylor, Schnackenberg, Freeman, \& Holland, 2005; Zhang et al., 2008), especially liquid chromatography coupled to mass spectrometry (LC/MS) have been widely used for HAAs analysis in these complex samples (Toribio et al., 2002; Barceló-Barrachina et al., 2004, 2006; Turesky et al., 2005). LC/MS is favoured because it provides both qualitative and quantitative information, without the requirement of analytes derivatization. Moreover, the use of narrow-bore reversed-phase UPLC columns in combination with electrospray ionisation (ESI) sources and tandem MS (MS/MS) instruments has allowed an improvement in the sensitivity and also a reduction in the analysis time (Barceló-Barrachina et al., 2006).

Our objectives were to estimate the content of HAAs in mutton shashlik and provide the guide to cooking practices. The influence of time, temperature, spices and heated area of meat on the formation of HAAs in mutton was investigated. The studied samples were prepared according to the information on dietary practices. After being validated in cooking experiments, it may be possible to predict the formation of heterocyclic amines in our cooking and to design safer cooking equipment and procedures. Accurate determination of HAAs in the samples was performed using the solid-phase extraction method described by Vollenbröker and Eichner (2000) and liquid chromatography coupled to tandem mass spectrometry (UPLC-ESI-MS/MS).

\section{Experimental}

\subsection{Chemicals}

The compounds studied were 2-amino-3-methylimidazo[4,5-f] quinoline (IQ), 2-amino-3,4-dimethylimidazo[4,5-f]quinoline (MeIQ), 2-amino-3,8-dimethylimidazo[4,5-f]quinoxaline (MeIQx), 2-amino-3,4,8- trimethylimidazo[4,5-f]quinoxaline (4,8-DiMeIQx), 2-amino-3,7,8- trimethylimidazo[4,5-f]quinoxaline (7,8-DiMeIQx), 2-amino-3,4,7,8- tetramethylimidazo[4,5-f]quinoxaline (TriMeIQx), 2-amino-1-methyl-6- phenylimidazo[4,5-b]pyridine (PhIP), 2-amino-1,6-dimethylimidazo [4,5-b]pyridine (DMIP), 2-amino9H-pyrido[2,3-b]indole $(\mathrm{A} \alpha \mathrm{C}), 2$-amino-3-methyl-9H-pyrido[2,3b]indole $(\mathrm{MeA} \alpha \mathrm{C}), 3$-amino-1,4- dimethyl-5H-pyrido[4,3-b]indole (Trp-P-1), 3-amino-1-methyl-5H-pyrido [4,3-b]indole (Trp-P-2), 2-amino-6-methyldipyrido[1,2-a:3',2'-d] imidazole (Glu-P-1), 2aminodipyrido[1,2-a:3',2'-d]imidazole (Glu-P-2), 1-methyl-9Hpyrido[3,4-b]indole (Harman), and 9H-pyrido[3,4-b]indole (Norharman) and were purchased from Toronto Research Chemicals Inc. (Toronto, Canada). HAAs methanolic stock standard solutions of $10 \mu \mathrm{g} / \mathrm{ml}$ were prepared and used for further dilutions. TriMeIQx was used as an internal standard in the experiment. Standards and samples were passed through a $0.2 \mu$ m nylon filter (Pall, USA) before injection into the UPLC system.

Methanol, acetonitrile, hexane, ethanol, and dichloromethane were of HPLC grade, and were all provided by Fisher (New Jersey, USA). Ultrapure water was obtained from a Milli-Q Plus $185^{\mathrm{TM}}$ coupled to an Elix $5^{\mathrm{TM}}$ system (Millipore, Schwalbach, Germany). Sodium hydroxide used for the sample treatment was obtained from BeiHua (Beijing, China) and chemicals for mobile phase preparation (ammonium acetate and acetic acid) were obtained from GFS Chemicals (Columbus, USA), and all were of analytical grade. Mobile phases were also filtered with a $0.2 \mu \mathrm{m}$ nylon filter (Pall, USA). LiChrolut EN SPE cartridges (200 $\mathrm{mg}, 3 \mathrm{ml}$ ) were supplied by Merck (Darmstadt, Germany).

\subsection{Instrument and MS conditions}

Chromatographic separation of HAAs was performed on a Waters Acquity ultra-performance liquid chromatography system, equipped with a quaternary pump system (Milford, MA, USA), using an Acquity BEH C8 column $(100 \mathrm{~mm} \times 2.1 \mathrm{~mm}$ i.d., $1.7 \mu \mathrm{m}$ particle size) (Waters, Milford, MA, USA). Optimum separation was achieved with a binary mobile phase at a flow rate of $0.3 \mathrm{ml} /$ min. Solvent A: acetonitrile; solvent B: $30 \mathrm{mM}$ acetic acid/ammonium acetate ( $\mathrm{pH} 4.5)$. The gradient elution programme was $0-$ $0.5 \mathrm{~min}, 20 \% \mathrm{~A}$; $0.5-2.0 \mathrm{~min}, 20-35 \% \mathrm{~A} ; 2.0-2.5 \mathrm{~min}, 35-45 \% \mathrm{~A}$; 2.5-3.0 min, 45-70\% A; 3.0-4.5 min, 70\% A; and 4.5-6.0 min, return to initial conditions, and equilibration of the column. The sample volume injected was $2 \mu \mathrm{l}$.

The UPLC system was coupled to a Quattro Premier XE triple quadrupole mass spectrometer (Micromass, Milford, MA, USA) using the electrospray ionisation source. For all compounds, the MS instrument was operated in the positive mode and the data were acquired in multiple-reaction monitoring (MRM). Source working conditions were as follows: cone voltage, $40 \mathrm{~V}$; capillary voltage, $3.0 \mathrm{kV}$; source temperature, $100^{\circ} \mathrm{C}$; desolvation temperature, $400{ }^{\circ} \mathrm{C}$; cone gas flow rate, $50 \mathrm{l} / \mathrm{h}$; desolvation gas flow rate, 800 l/h. Nitrogen (99.9\% purity) and argon (99.9999\% purity) were used as cone and collision gases, respectively. The MRM transitions as well as the individual collision energy voltages applied for the analysis are summarised in Table 1 . The dwell time established for each transition was $100 \mathrm{~ms}$, and the inter-scan delay was set at $10 \mathrm{~ms}$. Data acquisition was carried out by MassLynx v4.0 software.

\subsection{Sample treatment}

One of the aims of this study was to know the contents and concentration of HAAs formed under various normal cooking conditions. For this reason, the mutton was processed at cooking conditions similar to the normal habits previously. But the temperature of cooking of mutton shashlik was hard to be controlled when using the charcoal grilling. So we choose the oven instead to mimic the domestic cooking conditions because of adjustable time and temperature.

Raw mutton was purchased at a local supermarket in Beijing and frozen until use, then thawed at $4{ }^{\circ} \mathrm{C}$ overnight prior to cooking. Skin, fat parts, and bones were removed from lamb leg before cooking. The mutton samples were cut into cubes $(10 \mathrm{~mm} \times$ $10 \mathrm{~mm} \times 10 \mathrm{~mm})$, sliced $(50 \mathrm{~mm} \times 10 \mathrm{~mm} \times 10 \mathrm{~mm})$ and minced. The cooking method selected was roasting in oven and a Tefloncoated frying pan $(260 \mathrm{~mm} \times 260 \mathrm{~mm})$ was used. In our experiments, common flavours (oil, salt, sugar, ground white pepper powder, cumin powder, paprika powder, and five spices powder) were purchased from a local grocery store and they were mixed to the mutton. The raw mutton (weight $40 \pm 0.5 \mathrm{~g}$ ) was roasted in oven at a selected temperature and time. The samples for every conditional experiment were roasted in duplicate to obtain exact results. Finally, the samples were smashed by the chopper and stored at $-18^{\circ} \mathrm{C}$ until analysis.

To extract the analytes, the following purification method was used (Vollenbröker \& Eichner, 2000). First $1 \mathrm{~g}$ of sample was extracted in $10 \mathrm{ml}$ of methanolic $\mathrm{NaOH}$ (methanol/1 N NaOH 3:7) in a centrifuge tube, and after addition of the internal standard the supernatant of the centrifugated mixture was applied to the LiChrolut EN cartridge for SPE. After washing with $3 \mathrm{ml}$ of methanolic $\mathrm{NaOH}$ (methanol/0.1 N NaOH 55:45), $2 \times 0.7 \mathrm{ml}$ of hexane, $2 \times 0.7 \mathrm{ml}$ of ethanolic hexane (ethanol/hexane $1: 4$ ), $3 \mathrm{ml}$ of methanolic $\mathrm{NaOH}$ (methanol/0.1 N NaOH 55:45) again and finally $2 \times 0.7 \mathrm{ml}$ of hexane, again the extract was obtained by elution with $3 \mathrm{ml}$ of ethanolic methylene chloride (ethanol/methylene chloride 1:9). Then the eluent was evaporated under nitrogen and the residue was dissolved in $100 \mu \mathrm{l}$ of acetonitrile. Before injection into UPLC/MS/MS system the solution was passed through a $0.2 \mu \mathrm{m}$ nylon filter (Pall, USA). The limits of quantifica- 
Table 1

SRM transitions and limit of quantitation (LOQ) of method.

\begin{tabular}{|c|c|c|c|c|c|c|}
\hline \multirow[t]{2}{*}{ Analyte } & \multirow[t]{2}{*}{ Precursor ion $(m / z)$} & \multicolumn{2}{|l|}{ Quantitation } & \multicolumn{2}{|l|}{ Confirmation } & \multirow[t]{2}{*}{ LOQ $(\mathrm{pg} / \mathrm{g})$} \\
\hline & & Collision energy (eV) & Product ion $(\mathrm{m} / \mathrm{z})$ & Collision energy (eV) & Product ion $(m / z)$ & \\
\hline $\mathrm{MeA} \alpha \mathrm{C}$ & 198 & 181 & 20 & 154 & 28 & 20 \\
\hline $\mathrm{A} \propto \mathrm{C}$ & 184 & 167 & 24 & 140 & 30 & 24 \\
\hline PhIP & 225 & 210 & 25 & 183 & 32 & 12 \\
\hline Trp-P-1 & 212 & 195 & 25 & 168 & 30 & 37 \\
\hline Trp-P-2 & 198 & 154 & 30 & 181 & 25 & 62 \\
\hline Harman & 183 & 115 & 30 & 168 & 25 & 40 \\
\hline Norharman & 169 & 115 & 30 & 142 & 25 & 49 \\
\hline 4,8-DiMeIQx & 228 & 213 & 25 & 212 & 34 & 25 \\
\hline 7,8-DiMeIQx & 228 & 131 & 35 & 213 & 25 & 28 \\
\hline Glu-P-1 & 199 & 184 & 25 & 172 & 25 & 20 \\
\hline MeIQ & 213 & 198 & 25 & 197 & 35 & 13 \\
\hline MeIQx & 214 & 199 & 26 & 131 & 36 & 102 \\
\hline IQ & 199 & 157 & 30 & 184 & 24 & 200 \\
\hline Glu-P-2 & 185 & 158 & 24 & 131 & 26 & 22 \\
\hline DMIP & 163 & 148 & 20 & 147 & 30 & 40 \\
\hline
\end{tabular}
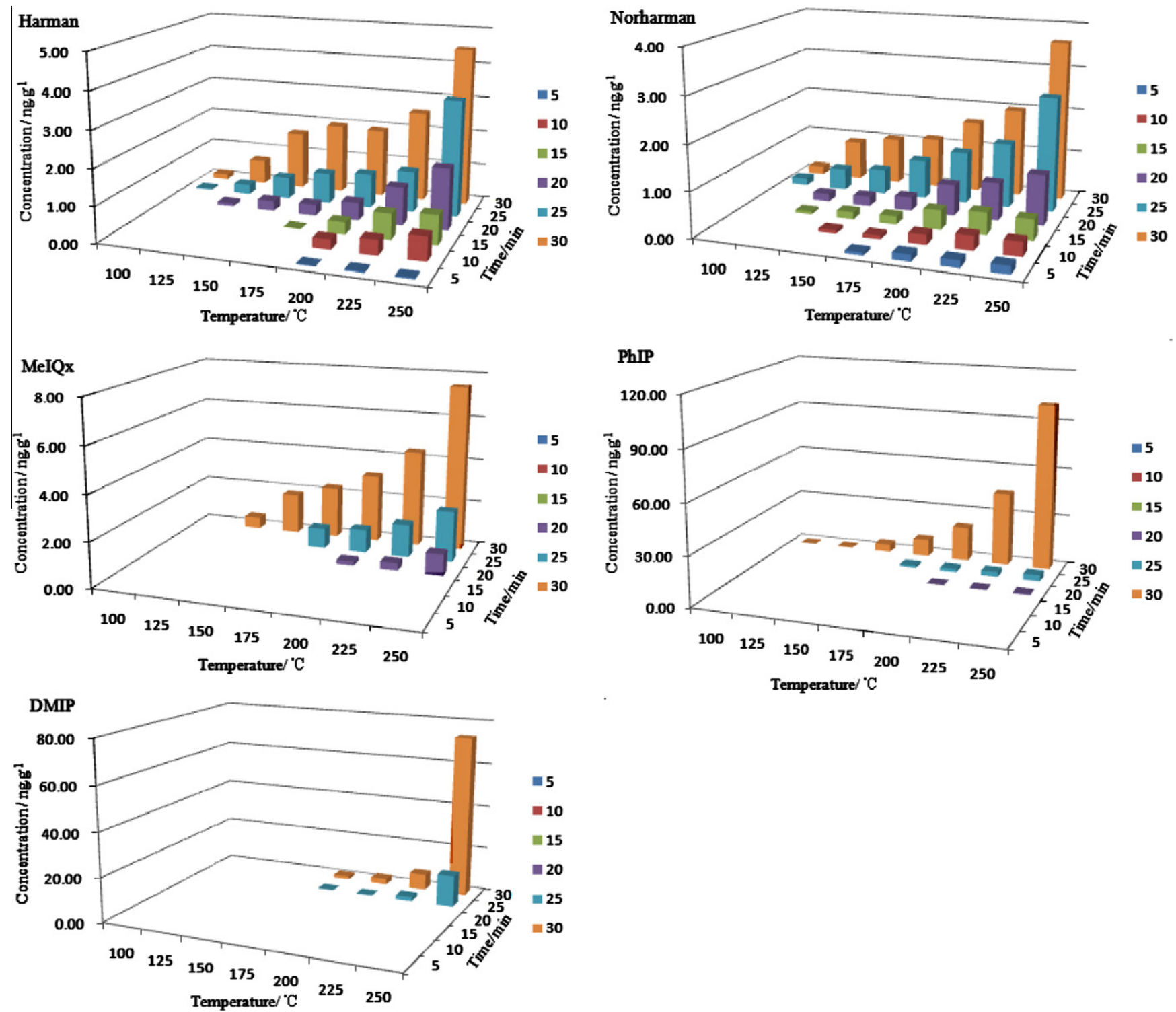

Fig. 1. The amount of Harman, Norharman, MeIQx, PhIP, and DMIP in roasted mutton influenced by cooking time and temperature. 
tion are shown in Table 1, which are similar to those obtained previously using other UPLC-MS/MS systems (Barceló-Barrachina et al., 2006).

\section{Results and discussion}

\subsection{The influence of cooking temperature and cooking time}

The HAAs formation as a function of time and temperature was measured in ground mutton roasted at a temperature of 100$250{ }^{\circ} \mathrm{C}$ at every $25^{\circ} \mathrm{C}$ for $5,10,15,20,25$ and $30 \mathrm{~min}$, respectively. The mutton cubes $(40 \mathrm{~g})$ without flavours were roasted on the Teflon-coated frying pan in the oven. Both time and temperature were found to have a strong impact on the formation of HAAs (Fig. 1). Seven HAAs (PhIP, Harman, Norharman, MeIQx, DMIP, 7,8-DiMeIQx, and MeIQ) were found, and 7,8-DiMeIQx and MeIQ were detected at a concentration of 0.67 and $1.36 \mathrm{ng} / \mathrm{g}$, respectively only in sample roasted at $250{ }^{\circ} \mathrm{C}$ for $30 \mathrm{~min}$. According to the data in Fig. 1, Harman and Norharman were detected in most samples, because the excess creatinine can improve the formation of Harman and Norharman in mutton (Jägerstad, Skog, Arvidsson, \& Solyakov, 1998), and the amounts of them increased continuously by prolonging the cooking time or by heightening the cooking temperature. No MeIQx was found at $100^{\circ} \mathrm{C}$ roasting even for $30 \mathrm{~min}$ or less than $15 \mathrm{~min}$ at any temperature. PhIP was not

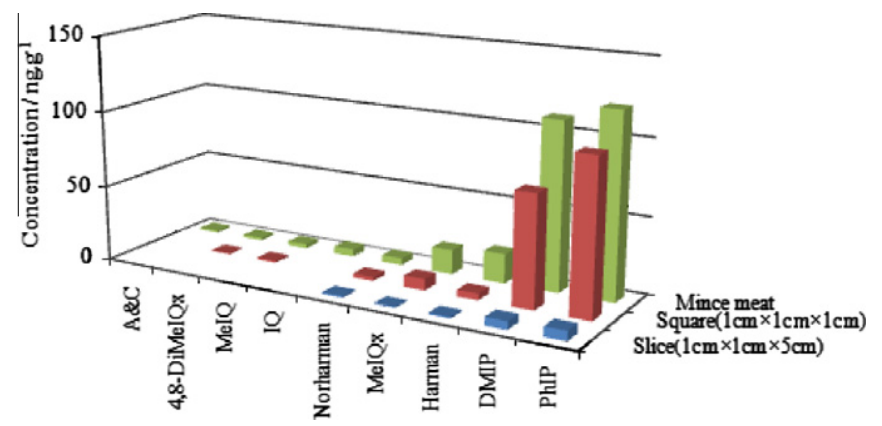

Fig. 2. The amount of HAAs in roasted mutton influenced by cooking area of heating surface. detected if the cooking time was less than 15 min at any temperature and increased greatly for $30 \mathrm{~min}$. DMIP was only detected when the cooking temperature exceeded $175^{\circ} \mathrm{C}$ and when the cooking time was longer than $20 \mathrm{~min}$. According to the data it could be concluded the levels of HAAs in cooked mutton are highly dependent on the cooking time and temperature and increased as the time was prolonged from 5 to $30 \mathrm{~min}$ and the temperature was heightened from 100 to $250^{\circ} \mathrm{C}$. These aminoimidazole-azaarenes, also known as thermic mutagens, are extremely mutagenic due to their formation at the much lower ordinary cooking temperature $\left(<300^{\circ} \mathrm{C}\right)($ Skog, 1993).

\subsection{The influence of area of heating surface}

The mutton samples (cubes, slice and minced meat, respectively) without flavours were roasted in oven at $250{ }^{\circ} \mathrm{C}$ for $30 \mathrm{~min}$. The content and levels of HAAs are shown in Fig. 2. The size order of surface areas were minced sample, cube sample, and sliced sample. The amount of HAAs in the roasted sliced mutton was the smallest of all and it increased by amplifying the area of heating surface. DMIP and PhIP were increased sharply in cube and minced samples compared with the sliced mutton and the levels of these even reached 110.7 and $120.37 \mathrm{ng} / \mathrm{g}$ in minced mutton. The A $\alpha \mathrm{C}$ and IQ were synthesised in the roasted minced mutton because of extreme cooking conditions, and the latter is a probable human carcinogen which should be avoided in our cooking.

\subsection{The influence of flavours}

The sample cubes with different flavours were roasted in oven at $250{ }^{\circ} \mathrm{C}$ for $20 \mathrm{~min}$. The flavours including salt, sugar, soy oil, white pepper powder, cumin powder, red pepper powder, and five spice powder were used in ordinary cooking of mutton shashlik in China. The effects of various flavours treatments on the HAAs formation at different cooking conditions are presented in Fig. 3. Every flavour could induce the synthesis of HAAs and different flavours may produce specific kind of HAAs. Five spice powder and red pepper powder induced more types of HAAs and the former resulted in producing MeA $\alpha$ C, PhIP, and 4,8-DiMeIQx, also increasing the amount of DMIP greatly. Salt, the pre-requisite flavour in cooking of mutton shashlik, induced synthesised Trp-P-2, MeIQ, IQ Glu-P-2, and DMIP, but the increasing extent was small. There was a little effect on the content and concentration of HAAs when

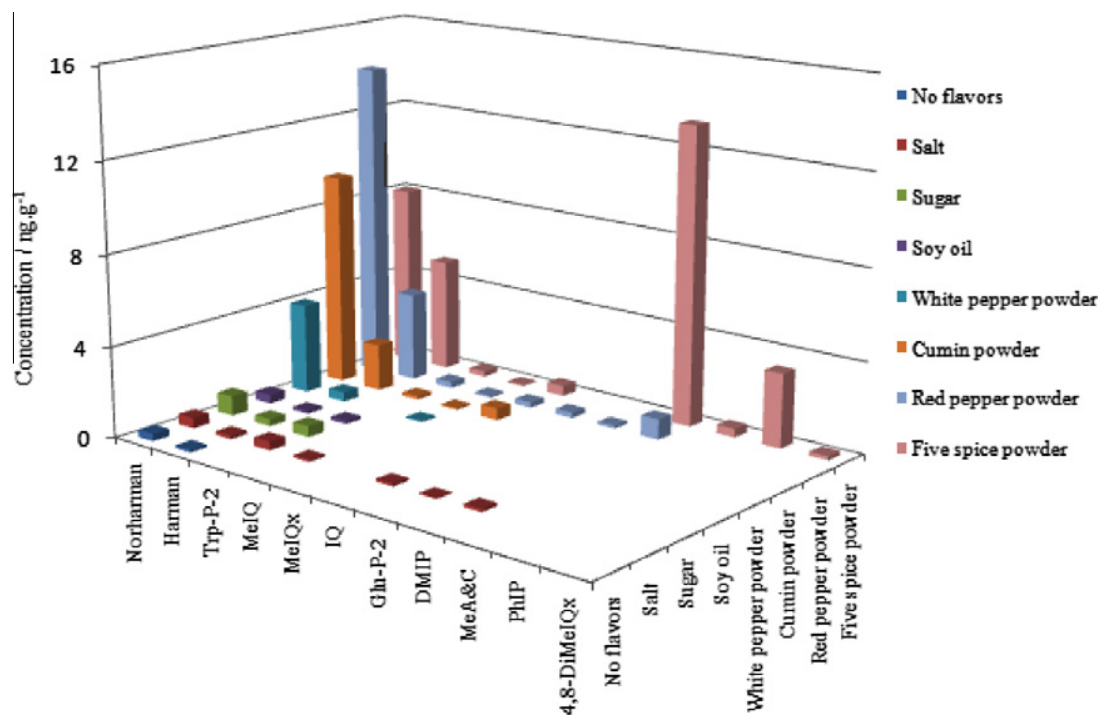

Fig. 3. The amount of HAAs in roasted mutton influenced by flavours. 
Table 2

Quantitation of HAs (ng/g extract) in five mutton shashliks bought in market using UPLC-ESI-MS/MS method.

\begin{tabular}{|c|c|c|c|c|c|}
\hline \multirow[t]{3}{*}{ Analyte } & \multicolumn{5}{|c|}{ Concentration (ng/g) } \\
\hline & \multicolumn{2}{|c|}{$\begin{array}{l}\text { Charcoal grilled mutton } \\
\text { shashlik }\end{array}$} & \multicolumn{3}{|c|}{ Electric grilled mutton shashlik } \\
\hline & Sample 1 & Sample 2 & Sample 3 & Sample 4 & Sample 5 \\
\hline $\mathrm{A} \alpha \mathrm{C}$ & 0.50 & 1.36 & 0.40 & 0.15 & n.d. \\
\hline PhIP & 0.31 & 0.79 & 0.50 & 0.07 & 0.18 \\
\hline Harman & 6.27 & 65.07 & 4.64 & 0.73 & 2.59 \\
\hline Norharman & 5.85 & 25.62 & 11.41 & 0.90 & 2.52 \\
\hline DMIP & 0.87 & 1.18 & 0.39 & 0.58 & 2.13 \\
\hline
\end{tabular}

using sugar, soy oil, and white pepper powder, respectively. The amounts of these were augmented largely by using the powder flavours. This has been explained as the result of increased transport of water-soluble precursors to the surface where the reactions occur (Jägerstad et al., 1998; Persson, Sjöholm, \& Skog, 2003). This phenomenon has been noted with carbohydrates that reduce cooking loss such as polysaccharides, starches, gums, and fibres that were shown to effectively decrease HAAs formation and mutagenicity.

\subsection{Determination of mutton shashlik from market}

Five mutton shashliks were bought in market. Two samples were grilled on charcoal and the other three samples were grilled on electric tube. The results are shown in Table 2. Harman, Norharman, DMIP, and PhIP were determined in all the samples and there was no $\mathrm{A} \alpha \mathrm{C}$ in sample 5. Due to different cooking conditions and sample shape the concentrations of Harman, Norharman, DMIP, $\mathrm{PhIP}$, and $\mathrm{A} \alpha \mathrm{C}$ were $0.40-1.36,0.07-0.50,0.73-65.07,0.90-25.62$, and $0.39-2.13 \mathrm{ng} / \mathrm{g}$. The amounts of HAAs in samples grilled on charcoal were higher than those of that grilled on electric tube because the temperature of charcoal's flame was higher than electric tube. In 1993, the International Agency for Research and Cancer, IARC, judged PhIP to be possible human carcinogens. Neither Harman nor Norharman is mutagenic but instead strengthens the genotoxicity of other HAAs (Sugimura, Nagao, \& Wakabayashi, 1982).

\section{Conclusions}

The analysis of five mutton shashliks bought in market in Beijing showed that a wide variety of HAAs was formed during the cooking process. Harman, Norharman, DMIP, PhIP, and A $\alpha \mathrm{C}$ were detected in levels of $0.40-1.36,0.07-0.50,0.73-65.07$, $0.90-25.62$, and $0.39-2.13 \mathrm{ng} / \mathrm{g}$, respectively. The amounts of heterocyclic aromatic amines in samples grilled on charcoal were much higher than those of that grilled on electric tube because the temperature of charcoal's flame was higher than electric tube. The high levels of HAAs were mutagens to lead to cancer. Moreover the influence factors, cooking temperature, cooking time, area of heating surface, and flavours, on the formation of HAAs in ground mutton roasted in the oven were investigated. According to the data it could be concluded that the levels of HAAs in cooked mutton were highly dependent on cooking time and temperature and increased as the time was prolonged from 5 to $30 \mathrm{~min}$ and the temperature was heightened from 100 to $250^{\circ} \mathrm{C}$. Meanwhile HAAs increased with the area of heating surface, and most powder flavours improved their formation. Sugar, soy oil, and white pepper powder have little effect on them. These analytical results will provide useful values to ordinary cookery for Chinese people and to epidemiologists for the determination of representative exposure of the Chinese population to HAAs.

\section{Acknowledgement}

This work was supported by the project of Chinese Academy of Inspection and Quanrantine (2007JK007).

\section{References}

Barceló-Barrachina, E., Moyano, E., \& Galceran, M. T. (2004). Determination of heterocyclic amines by liquid chromatography-quadrupole time-of-flight mass spectrometry. Journal of Chromatography A, 1054, 409-418.

Barceló-Barrachina, E., Santos, F. J., Puignou, L., \& Galceran, M. T. (2005). Comparison of dimethylformamide dialkylacetal derivatization reagents for the analysis of heterocyclic amines in meat extracts by gas chromatography-mass spectrometry. Analytica Chimica Acta, 545, 209-217.

Barceló-Barrachina, E., Moyano, E., Galceran, M. T., Lliberia, J. L., Bagó, B., \& Cortes, M. A. (2006). Ultra-performance liquid chromatography-tandem mass spectrometry for the analysis of heterocyclic amines in food. Journal of Chromatography A, 1125, 195-203.

Bermudo, E., Ruiz-Calero, V., Puignou, L., \& Galceran, M. T. (2005). Analysis of heterocyclic amines in chicken by liquid chromatography with electrochemical detection. Analytica Chimica Acta, 536, 83-90.

Borgen, E., \& Skog, K. Mol. (2004). Heterocyclic amines in some Swedish cooked foods industrially prepared or from fast food outlets and restaurants. Molecular Nutrition \& Food Research, 48, 292-298.

Busquets, R., Bordas, M., Toribio, F., Puignou, L., \& Galceran, M. T. (2004). Occurrence of heterocyclic amines in several home-cooked meat dishes of the Spanish diet. Journal of Chromatography B, 802, 79-86.

Casal, S., Mendes, E., Fernandes, J. O., Oliveira, M. B. P. P., \& Ferreira, M. A. (2004). Analysis of heterocyclic aromatic amines in foods by gas chromatography-mass spectrometry as their tert-butyldimethylsilyl derivatives. Journal of Chromatography A, 1040, 105-114.

Jägerstad, M., Grivas, S., Olsson, K., \& Negishi, C. (1984). Formation of 2-amino-3, 8dimethylimidazo[4,5- $f$ ]quinoxaline in a model system by heating creatinine, glycine and glucose. Mutation Research, 126, 239-244.

Jägerstad, M., Skog, K., Arvidsson, P., \& Solyakov, A. (1998). Chemistry, formation and occurrence of genotoxic heterocyclic amines identified in model systems and cooked foods. Zeitschrift für Lebensmittel - Untersuchung und Forschung, 207, 419-427.

Kataoka, H., \& Kijima, K. (1997). Analysis of heterocyclic amines as their Ndimethylaminomethylene derivatives by gas chromatography with nitrogenphosphorus selective detection. Journal of Chromatography A, 767, 187-194.

Martín-Calero, A., Ayala, J. H., González, V., \& Afonso, A. M. (2007). Determination of less polar heterocyclic amines in meat extracts fast sample preparation method using solid-phase microextraction prior to high-performance liquid chromatography-fluorescence quantification. Analytica Chimica Acta, 582, 259-266.

Martìn-Calero, A., Pino, V., Ayala, J. H., González, V., \& Afonso, A. M. (2007). Focused microwave-assisted extraction and HPLC with electrochemical detection to determine heterocyclic amines in meat extracts. Journal of Liquid Chromatography \& Related Technologies, 30, 27-42.

Nagao, M., Honda, M., Seino, Y., Yahagi, T., \& Sugimura, T. (1977). Mutagenicities of smoked condensates and the charred surface of fish and meat. Cancer Letter, 2, 221-226.

Ohgaki, H., Kusama, K., Matsukura, N., Morino, K., Hasegawa, H., Sato, S., et al. (1984). Carcinogenicity in mice of a mutagenic compound, 2-amino-3methylimidazo[4,5-f]quinoline, from broiled sardine, cooked beef and beef extract. Carcinogen, 5, 921-924.

Övervik, E., Kleman, M., Berg, I., \& Gustafsson, J. Å. (1989). Influence of creatine, amino acids and water on the formation of the mutagenic heterocyclic amines found in cooked meat. Carcinogen, 10, 2293-2301.

Pais, P., Salmon, C. P., Knize, M. G., \& Felton, J. S. (1999). Formation of mutagenic/ carcinogenic heterocyclic amines in dry-heated model systems, meats, and meat drippings. Journal of Agricultural and Food Chemistry, 47, 1098-1108.

Persson, E., Sjöholm, I., \& Skog, K. (2003). Effect of high water-holding capacity on the formation of heterocyclic amines in fried beefburgers. Journal of Agricultural and Food Chemistry, 51(16), 4472-4477.

Skog, K., \& Jägerstad, M. (1990). Effects of monosaccharides on the formation of food mutagens in model systems. Mutation Research, 230, 263-272.

Skog, K. (1993). Cooking procedures and food mutagens: a literature review. Food and Chemical Toxicology, 31, 655.

Solyakov, A., Skog, K., \& Jägerstad, M. (1999). Heterocyclic amines in process flavors, process flavor ingredients, bouillon concentrates and a pan residue. Food and Chemical Toxicology, 37, 1-11.

Sugimura, T., Nagao, M., \& Wakabayashi, K. (1982). Metabolic aspects of the comutagenic action of norharman. Advances in Experimental Medicine and Biology, 136, 1011-1025.

Toribio, F., Puignou, L., \& Galceran, M. T. (2000). Separation of heteroaromatic amines in food products. Journal of Chromatography B, 747, 171-202.

Toribio, F., Moyano, E., Puignou, L., \& Galceran, M. T. (2002). Multistep mass spectrometry of heterocyclic amines in a quadrupole ion trap mass analyzer. Journal of Mass Spectrometry, 37, 812-828.

Toribio, F., Busquets, R., Puignou, L., \& Galceran, M. T. (2007). Heterocyclic amines in griddled beef steak analysed using a single extract clean-up procedure. Food and Chemical Toxicology, 45, 667-675. 
Turesky, R. J., Taylor, J., Schnackenberg, L., Freeman, J. P., \& Holland, R. D. (2005). Quantitation of carcinogenic heterocyclic aromatic amines and detection of novel heterocyclic aromatic amines in cooked meats and grill scrapings by HPLC/ESI-MS. Journal of Agricultural and Food Chemistry, 53, 3248-3258.

Vollenbröker, M., \& Eichner, K. (2000). A new quick solid-phase extraction method for the quantification of heterocyclic aromatic amines. European Food Research and Technology, 212, 122-125.

Wakabayashi, K., Nagao, M., Esumi, H., \& Sugimura, T. (1992). Food-derived mutagens and carcinogens. Cancer Research, 52, 2092-2098.
Wakabayashi, K., \& Sugimura, T. (1998). Heterocyclic amines formed in the diet: Carcinogenicity and its modulation by dietary factors. Journal of Nutrition Biochemistry, 9, 604-612.

Zhang, F., Chu, X. G., Sun, L., Zhao, Y. S., Ling, Y., Wang, X. J., et al. (2008) Determination of trace food-derived hazardous compounds in Chinese cooked foods using solid-phase extraction and gas chromatography coupled to triple quadrupole mass spectrometry. Journal of Chromatography A, 1209 220-229. 